\title{
(2) OPEN ACCESS \\ State or market? How to effectively decrease alcohol-related crash fatalities and injuries
}

\author{
Jose I Nazif-Muñoz, ${ }^{1,2}$ Brice Batomen, ${ }^{3}$ Youssef Oulhote, ${ }^{4}$ Jack Spengler, ${ }^{2}$ Arijit Nandi ${ }^{3}$
}

- Additional material is published online only. To view please visit the journal online (http://dx.doi.org/10.1136/ jech-2019-213191)

${ }^{1}$ Université de Sherbrooke, Longueuil, Canada ${ }^{2}$ Harvard University, Boston, Massachusetts, USA

${ }^{3}$ McGill University, Montreal, Canada

${ }^{4}$ University of Massachusetts, Amherst, Massachusetts, USA

\section{Correspondence to}

Jose Ignacio Nazif-Munoz, Harvard University, Boston, MA 02215, USA;

jnazifmunoz@hsph.harvard.edu

Received 5 September 2019 Revised 18 February 2020 Accepted 22 February 2020

\begin{abstract}
Background It is estimated that more than 270000 people die yearly in alcohol-related crashes globally. To tackle this burden, government interventions, such as laws which restrict blood alcohol concentration (BAC) levels and increase penalties for drunk drivers, have been implemented. The introduction of private-sector measures, such as ridesharing, is regarded as alternatives to reduce drunk driving and related sequelae. However, it is unclear whether state and private efforts complement each other to reduce this public health challenge.

Methods We conducted interrupted time-series analyses using weekly alcohol-related traffic fatalities and injuries per 1000000 population in three urban conglomerates (Santiago, Valparaíso and Concepción) in Chile for the period 2010-2017. We selected cities in which two state interventions-the 'zero tolerance law' (ZTL), which decreased BAC, and the 'Emilia law' (EL), which increased penalties for drunk drivers-were implemented to decrease alcohol-related crashes, and where Uber ridesharing was launched.
\end{abstract}

Results In Santiago, the ZTL was associated with a 29.1\% decrease $(95 \% \mathrm{Cl} 1.2$ to 70.2$)$, the EL with a $41.0 \%$ decrease (95\% Cl 5.5 to 93.2) and Uber with a non-significant $28.0 \%$ decrease $(95 \% \mathrm{Cl}-6.4$ to 78.5$)$ in the level of weekly alcohol-related traffic fatalities and injuries per 1000000 population series. In Concepción, the EL was associated with a $28.9 \%$ reduction $(95 \% \mathrm{Cl} 4.3$ to 62.7$)$ in the level of the same outcome. In Valparaíso, the ZTL had a -0.01 decrease $(95 \% \mathrm{Cl}-0.02$ to -0.00$)$ in the trend of weekly alcoholrelated crashes per 1000000 population series.

Conclusion In Chile, concomitant decreases of alcoholrelated crashes were observed after two state interventions were implemented but not with the introduction of Uber. Relationships between public policy interventions, ridesharing and motor vehicle alcoholrelated crashes differ between cities and over time, which might reflect differences in specific local characteristics.

\section{INTRODUCTION}

Drunk driving is a major cause of global mortality. It is estimated that more than 270000 people die yearly in alcohol-related crashes across the world. ${ }^{1}$ To tackle this burden, many government interventions have been introduced, including laws which restrict blood alcohol concentration (BAC) levels in drivers, ${ }^{2}$ limit alcohol availability, ${ }^{3}{ }^{4}$ reduce the density of outlets, ${ }^{5}$ establish minimum legal age to drink, ${ }^{6}$ increase alcohol taxes, ${ }^{7}$ and promote checkpoints. ${ }^{8}$ These measures aim to reduce alcohol-impaired driving by decreasing either alcohol consumption or the probability of driving after already being impaired by alcohol.

While state interventions can be effective in reducing alcohol-related traffic fatalities and injuries. ${ }^{2-8}$ private initiatives have also been promoted to respond to this public health challenge. Designated driver programmes and smartphone-enabled network ridesharing have both been regarded as alternatives to complement state efforts. In the former, one individual agrees before a given social group to abstain from drinking alcohol in order to drive, so members of the group can be safely transported. In the latter, ridesharing networks provide alternatives to drinking and driving since individuals may opt for these private services when access to public transportation may be limited and/or traditional taxis costs may be higher. Yet, the literature on both initiatives is sparse. A systematic review suggested that designated driver programmes were not found to be effective in decreasing alcohol-related traffic outcomes. ${ }^{9}$ Research has also assessed the effects of network ridesharing on accidents, ${ }^{10-16}$ with six studies ${ }^{10-15}$ looking at the association between network ridesharing and alcohol-impaired driving in the United States (US). Results are mixed, with Martin-Buck, ${ }^{12}$ Greenwood and Wattal, ${ }^{13}$ Peck $^{14}$ and Morrison et al ${ }^{15}$ showing reductions in alcoholrelated crashes after Uber was introduced, whereas Brazil and Kirk ${ }^{10}$ and Dills and Mulholland ${ }^{11}$ did not observe any change in these outcomes.

In this study, we contribute to the body of research interested in assessing whether public and private initiatives influence alcohol-related crash fatalities and injuries. More specifically, we conducted a time-series analysis in Chile between 2010 and 2017 to empirically assess the association of (a) the zero tolerance law (ZTL), which determined the maximum legal BAC for fully licensed drivers to be $80 \mathrm{mg}$ of alcohol in $100 \mathrm{~mL}$ of blood, (b) the Emilia law (EL), which established that drivers who were intoxicated and responsible for serious injuries and/or fatalities must serve at least 1 year in prison and (c) the introduction of ridesharing on alcohol-related crash fatalities and injuries.

This work has the potential to advance research concerning the impact of population-level interventions on alcohol-related crash fatalities and injuries. First, to the best of our knowledge, all studies exploring the association between ridesharing and alcoholrelated incidents have been carried out in the US; however, results from these studies may not be generalizable to other settings with different epidemiologic profiles, mobility patterns and transport infrastructure. For instance, there were 1.3 road fatalities per 100000 registered vehicles in the US in 2016, whereas the corresponding rate was 3.8 per 100000 in Chile. ${ }^{17}$ Further, the number of registered vehicles per 1000 population in the US is $891 \mathrm{com}$ pared to 277 in Chile. ${ }^{17}$ Second, studies exploring 
ridesharing have not considered variation in drink and drive laws either across or within states, and therefore the associations of ridesharing may be biased due to unmeasured confounding by omitted co-interventions. Last, from a methodological point of view, the rich cross-urban conglomerate time-series data available for Chile allow us to control for the impact of confounding factors which change relatively slowly over time, such as age distribution, and for time-varying confounders such as seasonality with the help of Autoregressive Integrated Moving Average (ARIMA) models. ${ }^{18}$ Hence, Chilean data permit us to expand our road safety knowledge of Chile and the South American region more generally and contribute to our understanding of whether state efforts to curb drinking and driving and private ridesharing initiatives influence alcohol-related morbidity and mortality.

\section{STUDY CONTEXT}

In Chile from 2010 to 2017, approximately 14\% of all motor vehicle fatalities and $12 \%$ of all motor vehicle serious injuries were alcohol involved. ${ }^{19}$ To reduce the prevalence of alcohol-related crash fatalities and injuries, two different governments, with dissimilar political tendencies, enacted two laws: the ZTL and the EL. The first one was passed on 15 March 2012 and introduced two important changes regarding BAC levels. First, it lowered the maximum legal BAC for fully licensed drivers from $100 \mathrm{mg}$ of alcohol in $100 \mathrm{~mL}$ of blood (1.0\%) to $80 \mathrm{mg}(0.8 \%)$. With this law, any motor vehicle driver with BACs higher than $0.8 \%$ is subject to penal sanctions established by Chile's criminal code. ${ }^{20}$ Second, it established a new definition of driving under the influence of alcohol, since it decreased the legally accepted BAC from $0.5 \%$ to $0.3 \%$. Any driver with BACs higher than $0.3 \%$ and lower than $0.8 \%$ became subject to administrative sanctions established by Chile's traffic code. The second law was decreed on 16 September 2014. ${ }^{21}$ It introduced higher penalties for drivers responsible for alcohol-related crashes in which there were fatal or seriously injured victims. More specifically, it determined that these drivers would be imprisoned at least 1 year without the possibility of parole. It also established that hit-and-run and rejecting a breathalyser test were criminal offences, and these drivers would face both administrative and criminal sanctions. It is noteworthy, however, that between 2010 and 2017 Chile did not change any other law which could affect these outcomes. For instance, there were no changes to the minimum legal age to drink, restriction on advertising, promotion or sponsorship by producers of alcohol, minimum prices or sales restrictions related to prices of alcohol products, or taxes on alcohol-related products. ${ }^{22}$

In Chile prior to 2014, taxi transport services were exclusively provided by private companies registered in the Ministry of Transports and Telecommunications. During 2014, this service offered more than 265 million trips in Chile's capital city Santiago, and the number of taxis offering this service in Santiago, Valparaíso-Viña del Mar and Concepción was approximately $37000 .{ }^{23}$ In January 2014, Uber launched its application in Santiago, extending taxi transport services to its grounded traveller population. ${ }^{24}$ On 11 April 2016, this application was extended to the urban conglomerate of Valparaíso region, ${ }^{25}$ on 23 June 2016, to the urban conglomerate of Biobio region, ${ }^{26}$ and last in January 2017 to seven other cities (Antofagasta, Copiapó, Osorno, Puerto Montt, Rancagua, Temuco and Valdivia). ${ }^{27}$ By 2017, more than 2.3 million individuals had uploaded the Uber application (this corresponds to $12 \%$ of Chile's population), ${ }^{28}$ and the company had registered 80000 drivers. ${ }^{29}$ More than 100 million trips were registered during 2017. ${ }^{30}$ It is important to point out that while Uber is a service that typically requires a credit card for payment, in Chile both credit card and cash are available means to pay for services. Moreover, in Chile, the number of credit cards per capita in the adult population increased from 0.35 in 2010 to 1.02 in $2017 .^{31}$ The number of mobile phone contracts per capita in the adult population increased from 0.36 to 0.78 over the same period. ${ }^{32}$ (Please refer to online supplementary Appendix A to see trends in the number of credit cards per capita and the number of mobile phone contracts per capita.)

\section{METHODS}

\section{Study design}

We evaluated the impact of these three interventions in Chile using an interrupted time-series design. ${ }^{33}$ We focused our analyses on urban conglomerates, which were exposed to the three interventions of interest and had high values in the index of connectivity and mobility $(\geq 39)$ (this index considers various dimensions such as health, housing, sociocultural conditions and connectivity). ${ }^{34}$ Urban conglomerates eligible for inclusion in this study were: (a) had populations greater than 1000 000; (b) had municipalities with an index value of connectivity and mobility higher than 39 and (c) had Uber operations introduced between 1 January 2014 and 31 December 2016. We imposed these criteria in order to identify territories with sufficient populations, crashes and periods of analysis to detect changes in outcomes after the introduction of Uber.

After applying our eligibility criteria, our analyses included three urban conglomerates: (a) Santiago, with 35 municipalities (population 6266191$)^{35}$, (b) Concepción, with eight municipalities (population 1046970$)^{35}$ and (c) Valparaíso-Viña del Mar, with seven municipalities (population 1199 886)(please refer to online supplementary Appendix B to see every municipality included in the study). ${ }^{35}$ Our analytic sample included all alcohol-related crash fatalities and injuries between 1 January 2010 and 31 December 2017.

\section{Data}

We obtained data from the National Commission of Road Safety's Road Traffic Crashes Database. This organisation has used Chile's police force (Carabineros de Chile) reports to compile an extensive database of traffic fatalities, injuries and crashes in Chile from 1972 to the present. Fatalities are classified according to road user type (driver, passenger, motorcyclist, bicyclist and pedestrian), age, gender, time and day of the crash and whether the victims had been drinking alcohol. This database includes information, from all collisions involving injuries, about the characteristics of the collision, the vehicle and the individuals involved, including alcohol consumption.

\section{Dependent variable}

The dependent variable was the number of motor vehicle drivers and passengers who died or were injured in any alcohol-related traffic collision. We opted for this outcome, instead of the total number of crashes, since each of the interventions was expected to modify the decision of driving after having drunk alcohol. Variables common to the data set and relevant to our analyses were (a) crash date and time, (b) city and municipality in which the crash occurred and (c) police assessment of alcohol involvement (dichotomous). Using the municipality identification code, we produced a binary indicator identifying all alcohol-related crashes that occurred within the boundaries of the selected municipalities per urban conglomerate. We calculated rates per 1000000 population. The population denominator was chosen 
over the total number of crashes because the three interventions were likely to affect the latter as well, potentially biasing the results. In sensitivity analyses, however, we analysed each urban conglomerate with the total number of crashes as both denominator and outcome. Results were qualitatively similar with crash as denominator, and overall no effects were found when used as outcome (see results in online supplementary Appendix C). We also did an analysis stratifying by sex and results were robust (results available upon request).

For this study, a weekly time series is the most appropriate since it better captures the distribution of alcohol-related crashes. Further, following Morrison et al (2018), ${ }^{15}$ we also tabulated all alcoholinvolved crash fatalities and injuries from 12:00 AM Wednesday to 11:59 PM Tuesday. In this way, crashes occurring on weekends may not be randomly separated into different weeks. Furthermore, weekend nights are peak periods for alcohol-involved crashes in Chile. ${ }^{19}$

\section{Interventions}

The main interruptions of interest were when the two laws were introduced and the dates that Uber operations were launched. To identify the dates indicating when Uber was launched in the selected urban conglomerates, we studied online papers and Uber press conferences carried out in Chile. A summary of the interventions for the three urban conglomerates is presented in table 1 . For the weeks in which these changes occurred, we specified dichotomous independent variables in step (level) form ( 0 for weeks before the change and 1 in the week of the change and for subsequent weeks). This variable allows us to estimate level changes in the series. We also considered trend (slope) changes of each intervention. For this, we count the number of weeks after each intervention at time $t$, coded 0 before the intervention and increasing successively starting at 1 week after the introduction of each intervention to the number of time points $t$ (418). Trend changes allow us to assess whether the interventions were short term (immediate but not sustained), and long term (ie, immediate and sustained, delayed and sustained and delayed with diminishing or increasing gains over time).

\section{Statistical analysis}

To explore the relation between these three interventions and all alcohol-related crash injuries and fatalities, we carried out interrupted time-series analyses ${ }^{36}$ using the PROC ARIMA (Autoregressive Integrated Moving Average) procedure in SAS 9.4. ${ }^{37}$ (We also repeated the analyses using Stata software and the results are presented in online supplementary Appendix D.) This statistical approach needs at least 50 temporal units and assumes that the dependent variable is approximately normally distributed $^{36}$ and that the time series should be stationary (ie, with constant mean and variance).

To detect whether each series was stationary, we assessed the presence of unit roots using the Dickey-Fuller test and fitting higher-order AR models. Once we identified the series to be

\begin{tabular}{lccc}
\hline Table 1 & Interventions in three urban conglomerates, Chile, 2014-2016 \\
\hline $\begin{array}{l}\text { Urban } \\
\text { conglomerate }\end{array}$ & Zero tolerance law & Emilia law & Uber launch \\
\hline $\begin{array}{l}\text { Santiago } \\
\text { Concepción }\end{array}$ & 15 March 2012 & 16 September 2014 & 23 June 2016 \\
\hline $\begin{array}{l}\text { Valparaíso-Viña del } \\
\text { Mar }\end{array}$ & & 11 April 2016 \\
\hline
\end{tabular}

stationary, we proceeded to select which AR or ARMA model best fit each series. For this, we assessed both the autocorrelation and partial autocorrelation functions of each model and applied the Ljung-Box test to model residuals at lags, 24 and 48. With these numbers of lags, we were better equipped to detect the presence of white noise throughout the weekly series.

To investigate the association of each intervention on alcohol-related crash injuries and fatalities, we applied three models: (1) the 'Naïve model' (Equation 1), (2) the 'Uber-oriented model' (Equation 2) and (3) the 'Full model' (Equation 3). The specification of each equation can be found in online supplementary Appendix E. The 'Naïve model' only considers whether each intervention had an effect on the level of the series. We call this model 'Naïve' since we assumed interventions do not vary in their intensity over time. However, theoretically and empirically this can be inadequate since effects of interventions can be short or long term, ${ }^{18}$ and for the case of Chile, road safety policies have been found to be short term. ${ }^{38}$ As such, the two other models assessed whether the two laws had either short-term or long-term associations, or both, on the series. The difference between the 'Uberoriented model' and the 'Full model' is that the former only allows Uber's introduction to affect the level of the series, whereas the latter assesses whether the introduction of Uber changed the trend.

\section{RESULTS}

\section{Alcohol-related crash fatalities and injuries in Santiago}

Three main results are presented in table 2 . First, the three models show that the ZTL was associated with a level change in the series. The most conservative result is depicted in the 'Full model', which indicated that the law was associated with a -0.34 reduction $(95 \% \mathrm{CI}-0.67$ to -0.02$)$ in the level of alcoholrelated traffic fatalities and injury rates per 1000000 population. This corresponds to a $29.1 \%$ decrease (95\% CI 1.2 to 70.2 ). Second, the EL ('Full model') was associated with a -0.48 decrease $(95 \%$ CI -0.89 to -0.07$)$ in the level of alcoholrelated traffic fatalities and injuries per population. This corresponds to $41.0 \%$ decrease (95\% CI 5.5 to 93.2). A slight change of $-0.02(95 \%$ CI -0.04 to -0.00$)$ in the weekly trend following its introduction was also observed. Last, in the 'Full model', Uber was not observed to have an effect on the outcome of interest. We estimated a -0.33 decrease $(95 \%$ CI -0.74 to 0.09 ) in the level of alcohol-related crash fatalities and injury rate per 1000000 population. This corresponds to a nonsignificant $28.0 \%$ decrease $(95 \%$ CI -6.4 to 78.5$)$. There was also an increase in the weekly trend in fatalities and injury rate by 0.02 (95\% CI 0.00 to 0.04) per week. Ljung-Box tests and AIC values for each model and city are presented in online supplemen tary Appendix F.

\section{Interventions on alcohol-related crash fatalities and injuries in Concepción}

In table 3, we provide the results corresponding to Concepción. Regardless of the model, the ZTL was not associated with alcohol-related crash fatalities and injuries. The EL, on the other hand, was associated with a short-term reduction in both the 'Uber-oriented model' and the 'Full model'. In the 'Full model', we estimated a -1.02 decrease $(95 \% \mathrm{CI}-1.87$ to -0.18$)$ in the level of the main outcome after the EL was introduced. This is equivalent to a $28.9 \%$ reduction (95\% CI 4.3 to 62.7 ). We estimated a 0.02 increase (95\% CI 0.01 to 0.04 ) in the trend of the rate of alcohol-related crash fatalities and injuries. Last, Uber 
Table 2 Associations of three interventions on alcohol-related motor vehicle crashes rates per 10000000 population, Concepción, 1 January 2010 -31 December 2017 (SARIMA $(2,0,0)(1,0,0) 8)$ for residuals

\begin{tabular}{|c|c|c|c|c|c|c|c|c|c|}
\hline & \multicolumn{3}{|c|}{ Naïve model } & \multicolumn{3}{|c|}{ Uber-oriented model } & \multicolumn{3}{|c|}{ Full model } \\
\hline & $\boldsymbol{\beta}$ & $95 \% \mathrm{Cl}$ & $P$-value & $\boldsymbol{\beta}$ & $95 \% \mathrm{Cl}$ & $P$-value & $\boldsymbol{\beta}$ & $95 \% \mathrm{Cl}$ & $P$-value \\
\hline Time & 0.003 & 0.001 to 0.004 & 0.006 & 0.001 & -0.002 to 0.005 & 0.458 & 0.001 & -0.002 to 0.005 & 0.415 \\
\hline Zero tolerance law & -0.451 & -0.690 to -0.229 & 0.002 & -0.404 & -0.733 to -0.075 & 0.015 & -0.341 & -0.665 to -0.017 & 0.036 \\
\hline Zero tolerance law change in trend & & & & 0.002 & -0.003 to 0.008 & 0.433 & 0.001 & -0.005 to 0.006 & 0.846 \\
\hline Emilia law & -0.098 & -0.369 to 0.173 & 0.476 & -0.141 & -0.4265 to 0.144 & 0.331 & -0.481 & -0.885 to -0.077 & 0.020 \\
\hline Emilia law change in trend & & & & -0.000 & -0.005 to 0.004 & 0.844 & -0.019 & -0.035 to -0.002 & 0.027 \\
\hline Uber & -0.028 & -0.285 to 0.229 & 0.830 & -0.080 & -0.444 to 0.285 & 0.668 & -0.329 & -0.746 to 0.089 & 0.122 \\
\hline Uber trend & & & & & & & 0.020 & 0.002 to 0.037 & 0.025 \\
\hline Constant & 1.090 & 0.948 to 1.239 & $<0.001$ & 1.175 & 0.943 to 1.407 & $<0.001$ & 1.172 & 0.950 to 1.395 & $<0.001$ \\
\hline
\end{tabular}

Autoregressive, Akaike information criterion and Ljung-Box tests values for each model are available in online supplementary Appendix F.

Table 3 Associations of three interventions on alcohol-related motor vehicle crash rates per 10000000 population, Concepción, 1 January 2010 31 December 2017 (ARMA $(2,0))$ for residuals

\begin{tabular}{|c|c|c|c|c|c|c|c|c|c|}
\hline & \multicolumn{3}{|c|}{ Naïve model } & \multicolumn{3}{|c|}{ Uber-oriented model } & \multicolumn{3}{|c|}{ Full model } \\
\hline & $\beta$ & $95 \% \mathrm{Cl}$ & $P$-value & $\boldsymbol{\beta}$ & $95 \% \mathrm{Cl}$ & $P$-value & $\beta$ & $95 \% \mathrm{Cl}$ & $P$-value \\
\hline Time & 0.003 & -0.002 to 0.008 & 0.269 & -0.006 & -0.014 to 0.003 & 0.195 & -0.006 & -0.014 to 0.003 & 0.189 \\
\hline Zero tolerance law & -0.676 & -1.424 to 0.072 & 0.077 & -0.108 & -0.907 to 0.690 & 0.790 & -0.109 & -0.896 to 0.677 & 0.785 \\
\hline Zero tolerance law change in trend & & & & 0.008 & -0.004 to 0.019 & 0.185 & 0.008 & -0.003 to 0.019 & 0.178 \\
\hline Emilia law & -0.195 & -0.908 to 0.518 & 0.591 & -0.694 & -1.468 to 0.081 & 0.079 & -1.024 & -1.867 to -0.181 & 0.017 \\
\hline Emilia law change in trend & & & & 0.014 & 0.002 to 0.026 & 0.026 & 0.021 & 0.007 to 0.035 & 0.004 \\
\hline Uber & 0.463 & -0.195 to 1.121 & 0.168 & -0.627 & -1.589 to 0.335 & 0.201 & -0.545 & -1.498 to 0.405 & 0.259 \\
\hline Uber trend & & & & & & & -0.018 & -0.037 to 0.001 & 0.070 \\
\hline Constant & 3.051 & 2.630 to 3.472 & $<0.001$ & 3.551 & 2.966 to 4.135 & $<0.001$ & 3.549 & 2.974 to 4.124 & $<0.001$ \\
\hline
\end{tabular}

Autoregressive, Akaike information criterion and Ljung-Box test values for each model are available in online supplementary Appendix F.

was not associated with the rate of alcohol-related traffic fatalities in any of the models.

\section{Interventions on alcohol-related crash fatalities and injuries in Valparaiso-Viña del Mar}

We highlight three main results from table 4. First, the ZTL had a delayed and slight sustained effect, with the 'ZTL change in trend' parameter indicating a -0.01 reduction $(95 \% \mathrm{CI}-0.02$ to -0.00$)$ in the weekly rate of alcohol-related crash fatalities and injuries per 1000000 population. Second, the EL was not associated with the outcome in any model. Last, there was no evidence for an impact of Uber in the last two models, although we observed a 0.49 increase $(95 \%$ CI -0.03 to 1.00 ) in the level of the outcome in the 'Naïve model'.

Figures $1-4$ present the observed values for alcohol-related crash fatalities and injuries and their predicted values per urban conglomerate. Changes in predicted values due to the interventions are clearly visible in Santiago (figure 1 and figure 2), which shows that rates of alcohol-related crash fatalities and injuries dropped substantially after both laws for the best two models. In Concepción (figure 3), we observed a short-term reduction in the level of fatalities and injuries after the EL, followed by an increasing trend that was mitigated by the introduction of Uber. Last, in Valparaíso-Viña del Mar (figure 4), we observed a delayed beneficial effect of the ZTL and the subsequent increase in the EL trend.

\section{DISCUSSION}

In Chile, state interventions seem to prevent alcohol-related collisions more successfully than the introduction of Uber. This time- series analysis, conducted in three urban conglomerates where two state interventions were introduced, demonstrates that in highly populated locations these efforts can be effective. However, their sustainability may be a function of geographical location characteristics. We also examine whether ridesharing had spillover effects in this context; nevertheless, we did not consistently observe positive externalities on our primary outcome.

We explored whether a combination of public and private efforts would reduce the incidence of alcohol-related crash fatalities and injuries since reducing BAC levels (ZTL), introducing higher penalties for individuals driving under the influence of alcohol (EL) and the lower perceived financial and expediency costs associated with ridesharing (Uber) would have decreased the likelihood that someone would have driven after already being impaired by alcohol. As such, we assessed whether each intervention could have either a short term, abrupt and permanent, delayed and sustained or delayed with diminishing or increasing gains over time. Findings suggest that legislative reforms were more effective than the introduction of ridesharing in the three urban areas evaluated. However, these state efforts are not homogenous across the urban conglomerates analysed. In Santiago, both laws were effective in reducing alcohol-related crash fatalities and injuries. In Concepción, only the EL shows a sharp short-term association. Last, in Valparaíso-Viña del Mar, we observed a delayed and mild association of the ZTL. Surprisingly, the introduction of Uber in Chile did not seem to influence trends.

The observed variability in the estimated relationships across cities and interventions may be due to differing circumstances 
Table 4 Associations of three interventions on alcohol-related motor vehicle crash rates per 10000000 population, Valparaíso-Viña del Mar, 1 January 2010-31 December 2017 (ARMA $(1,0)$ ) for residuals.

\begin{tabular}{|c|c|c|c|c|c|c|c|c|c|}
\hline & \multicolumn{3}{|c|}{ Naïve model } & \multicolumn{3}{|c|}{ Uber-oriented model } & \multicolumn{3}{|c|}{ Full model } \\
\hline & $\boldsymbol{\beta}$ & $95 \% \mathrm{Cl}$ & $P$-value & $\beta$ & $95 \% \mathrm{Cl}$ & $P$-value & $\boldsymbol{\beta}$ & $95 \% \mathrm{Cl}$ & $P$-value \\
\hline Time & -0.003 & -0.007 to 0.001 & 0.129 & 0.003 & -0.004 to 0.010 & 0.466 & 0.003 & -0.004 to 0.010 & 0.466 \\
\hline Zero tolerance law & -0.370 & -0.955 to 0.215 & 0.214 & -0.394 & -1.034 to 0.246 & 0.227 & -0.394 & -1.034 to 0.246 & 0.227 \\
\hline Zero tolerance law change in trend & & & & -0.010 & -0.019 to -0.001 & 0.026 & -0.010 & -0.019 to -0.001 & 0.026 \\
\hline Emilia law & 0.173 & -0.378 to 0.724 & 0.537 & 0.421 & -0.184 to 1.026 & 0.172 & 0.316 & -0.396 to 1.028 & 0.384 \\
\hline Emilia law change in trend & & & & 0.006 & -0.003 to 0.016 & 0.204 & 0.009 & -0.005 to 0.023 & 0.198 \\
\hline Uber & 0.488 & -0.028 to 1.003 & 0.064 & 0.351 & -0.416 to 1.117 & 0.369 & 0.322 & -0.452 to 1.095 & 0.414 \\
\hline Uber change in trend & & & & & & & -0.004 & -0.020 to 0.011 & 0.583 \\
\hline Constant & 2.440 & 2.110 to 2.777 & $<0.001$ & 2.111 & 1.642 to 2.582 & $<0.001$ & 2.112 & 1.642 to 2.582 & $<0.001$ \\
\hline
\end{tabular}

Autoregressive, Akaike information criterion and Ljung-Box tests values for each model are available in online supplementary Appendix F.

in which the laws were enforced, different levels of alcohol consumption in each analysed city, and how ridesharing operations may have changed over time. First, with respect to enforcement, one study ${ }^{38}$ suggested that police controls may act rapidly after a legislative change occurs, but this response is rarely sustained. This may explain the short-term and delayed association observed in Concepción and Valparaíso-Viña del Mar, respectively. Second, alcohol consumption studies carried out in Chile ${ }^{39}$ have suggested that high-risk municipalities are mostly located in Concepción. This pattern is thus likely associated with high consumption of home-made or illegal alcohol, as well as poor response of health services to provide treatment for diseases related to alcohol consumption. While Chile is a centralised state, its public resources are not evenly distributed across cities. This has been particularly noticeable for road safety policies. $^{40} \mathrm{~A}$ combination of high alcohol consumption with a weak state intervention may explain what we observed in Concepción. Last, while Uber entered in these cities with considerable publicity, and currently there are more Uber drivers than taxi drivers in these cities, its exponential rise in popularity may have been interrupted on different occasions since private taxi representatives and drivers explicitly boycotted its functioning on at least five occasions in 2016 and 2017..$^{41}$ This may have discouraged potential Uber drivers from joining the company or restricted their journeys, and thus ridesharing supply may not have kept pace with demand from potential users who may have consumed alcohol. Even further, 10\% of Uber drivers are women, and recent reports suggest that they are less likely to drive at night since they can be subject to attacks by other taxi drivers, and when they do, they generally avoid transporting individuals under the influence of alcohol. ${ }^{41}$

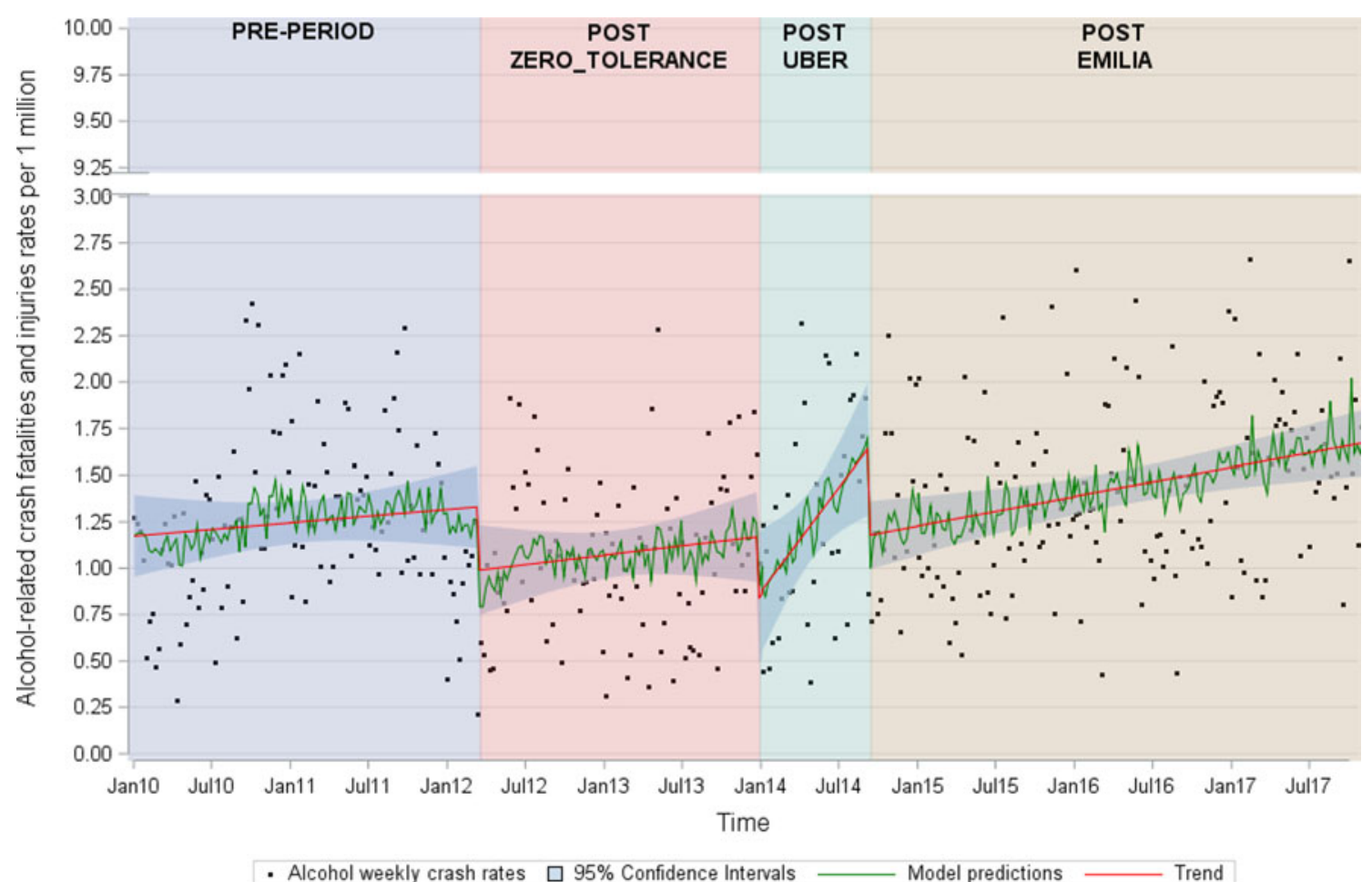

Figure 1 Weekly time-series plots for the proportion of all alcohol-related crash fatalities and injuries in Santiago (1 January 2010 to 30 December 2017 ). The predicted values for Santiago are obtained from an interrupted time-series model (SARIMA $(2,0,0)(1,0,0) 8)$ from Equation 3 (full model). 


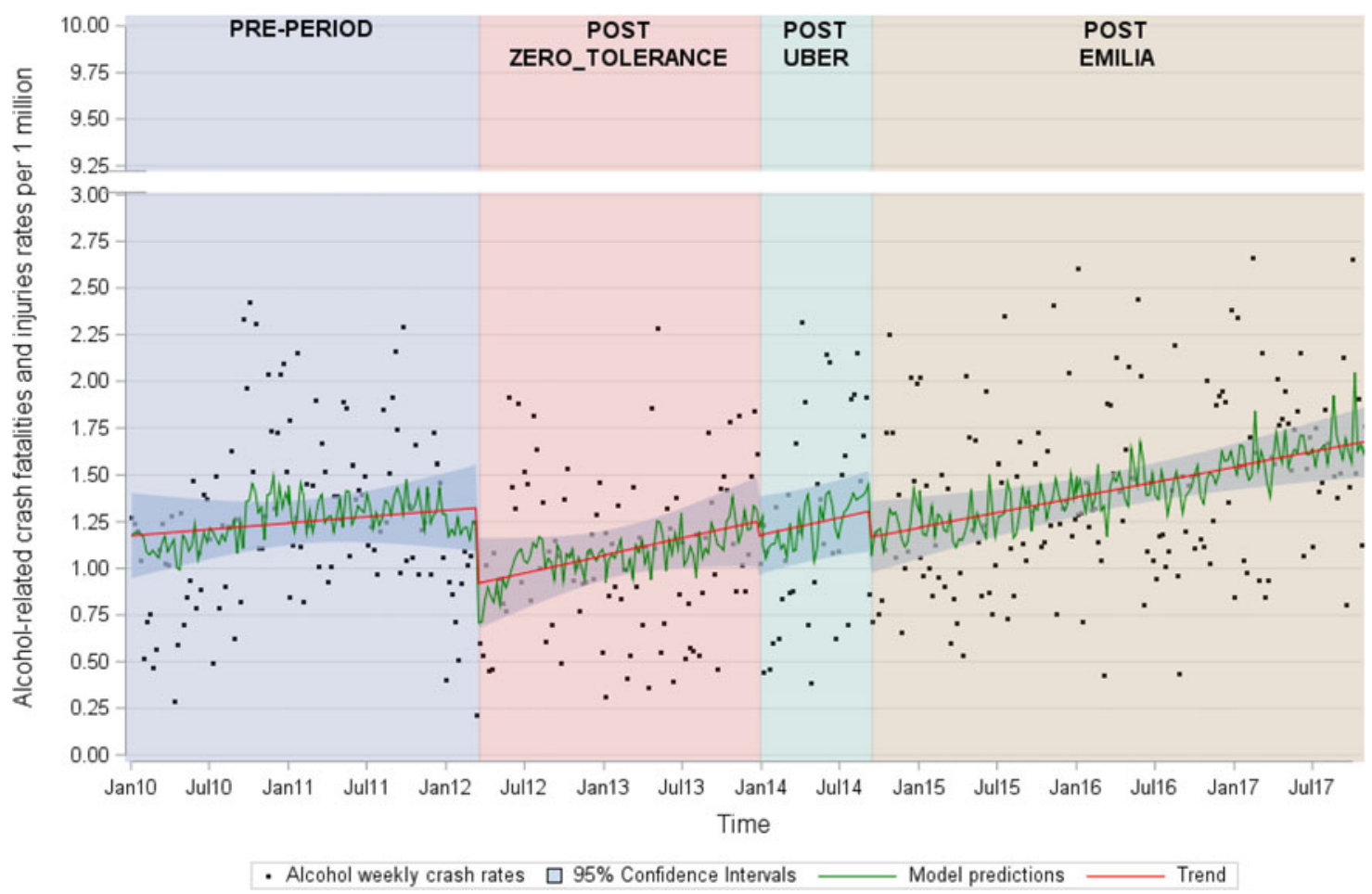

Figure 2 Weekly time-series plots for the proportion of all alcohol-related crash fatalities and injuries in Santiago (1 January 2010 to 30 December 2017). The predicted values for Santiago are obtained from an interrupted time-series model (SARIMA $(2,0,0)(1,0,0) 8)$ from Equation 2 (Uber-oriented model).

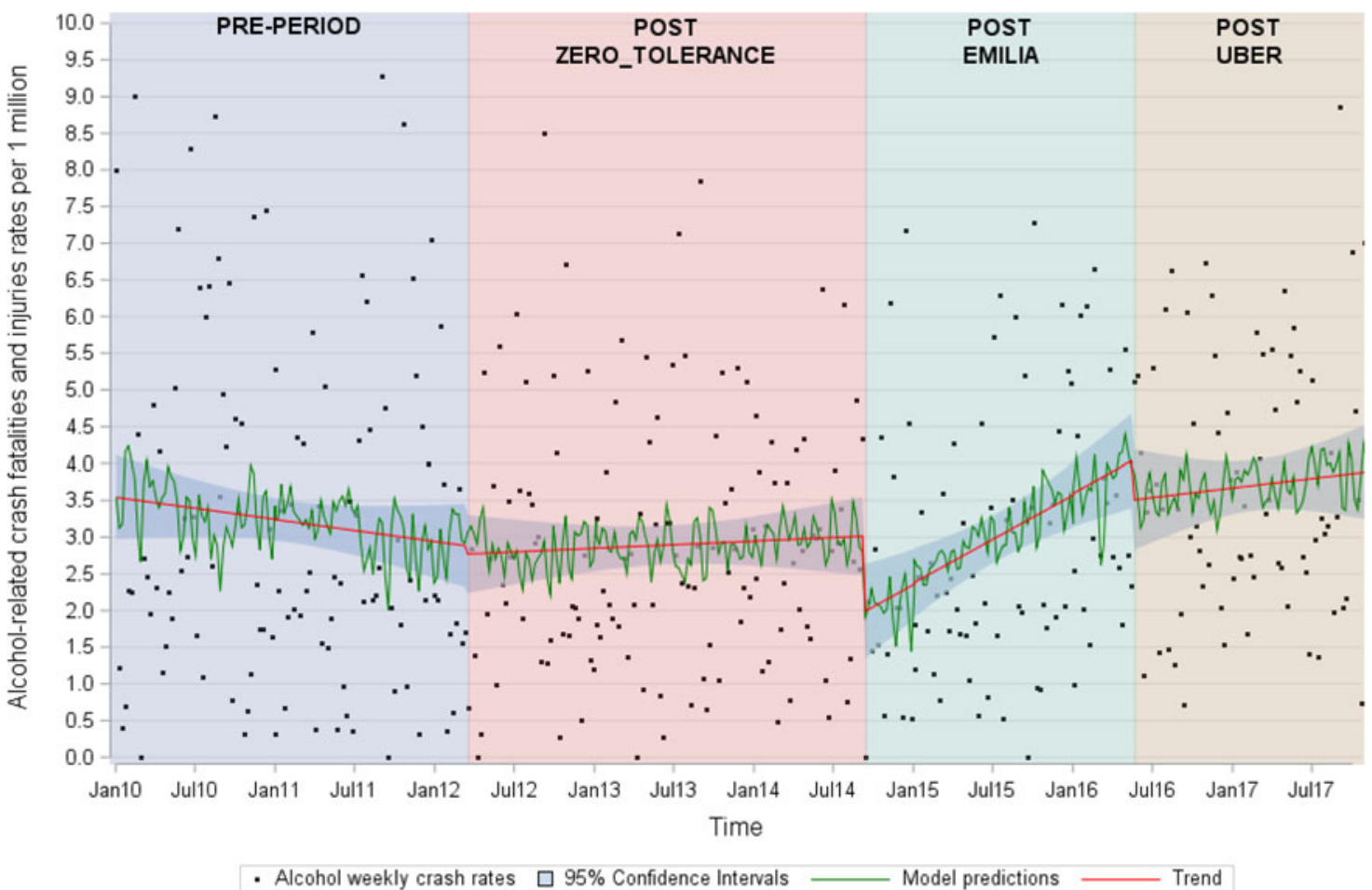

Figure 3 Weekly time-series plots for the proportion of all alcohol-related crash fatalities and injuries in Concepción (1 January 2010 to 30 December 2017). The predicted values for Concepción are obtained from an interrupted time-series model (ARMA $(2,0)$ ) from Equation 3 (full model).

Our findings may explain the mixed results obtained in a previous time-series study using ARIMA modelling. ${ }^{15}$ Indeed, associations differ when different geographic scales are used. In our study, the largest urban conglomerate, Santiago, clearly benefited from the two reforms and Uber had a null impact. By contrast, in Valparaíso-Viña del Mar and Concepción, urban conglomerates with 1000000 population, we did not observe sustained changes from the two state interventions or with the 


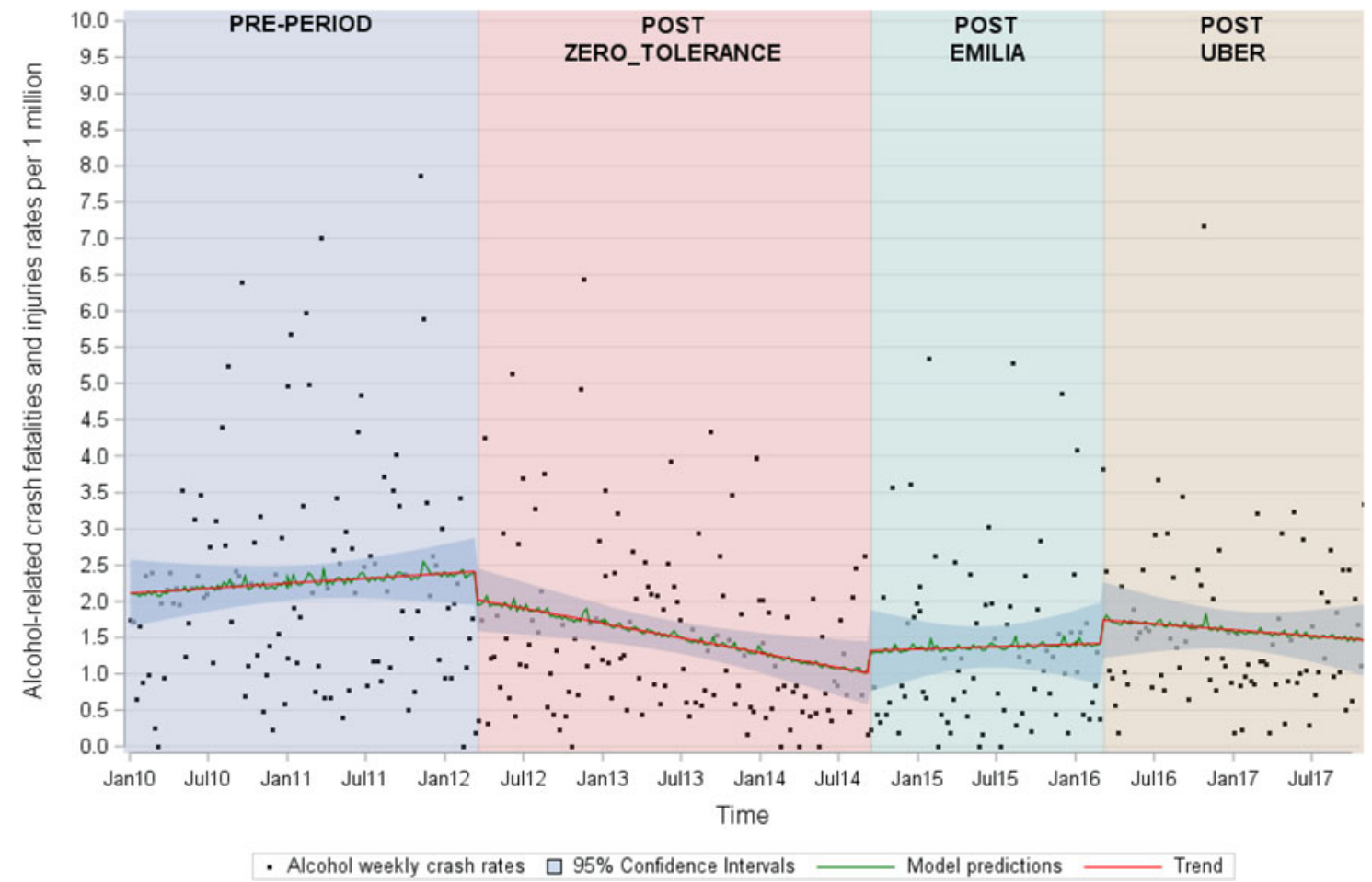

Figure 4 Weekly time-series plots for the proportion of all alcohol-related crash fatalities and injuries in Valparaíso-Viña del Mar (1 January 2010 to 30 December 2017 ). The predicted values for Valparaíso-Viña del Mar are obtained from an interrupted time-series model (ARMA $(1,0))$ from Equation 2 (Uber equation model).

introduction of ridesharing. It is possible that smaller cities may require a higher proportion of police enforcement practices and more aggressive expansion and marketing of ridesharing services than larger cities. However, analyses considering the volume of police enforcement and the number of ridesharing trips are required to identify how these two mechanisms operate. In terms of properly measuring the impact of ridesharing, it is important to note that operationalisations which capture exponential growth should also be advanced since this specific pattern can have other effects on alcohol-related crashes but also in the total number of crashes.

There were several limitations to our approach. First, police assessment of alcohol involvement and classification of injuries and fatalities may not be consistent over time or across cities, and this measurement error might bias results. However, while differences between alcohol-related crashes between Santiago and Concepción could be an expression of measurement error, it is noteworthy that binge drinking for individuals aged 17-35 increased from 3.7\% in 2012 to $9.5 \%$ in 2016 in Concepción, compared to $6.1 \%$ to $7.4 \%$ in Santiago; these different patterns might contribute to differential effects across cities. ${ }^{42}$ Second, although we selected cities in which Uber operations occurred at different times, we did not have continuous measures of rideshare utilisation (eg, counts of Uber journeys), the supply of this service by the gender of drivers, nor whether regular taxi services varied over time after the introduction of Uber. These missing elements would help to better understand the relation between ridesharing and alcohol-related crashes. Third, we cannot rule out the potential for unmeasured time-varying confounding, and particularly the potential for other coincident externalities such as an increase in gas prices which reduce overall mobility to impact rates of alcohol-related crash fatalities and injuries.
This study highlights that state interventions in centralised countries may reduce alcohol-involved crashes, and thus should become or remain a priority. These associations, nevertheless, are likely to differ across urban conglomerates and over time. Future studies should thus seek to identify the key aspects of these differential relationships and the characteristics of urban conglomerates where the public health impacts of state interventions are the weakest. This study also adds a quote of healthy skepticism to public health solutions based on technological determinism. In other words, technological changes can indeed be excellent platforms to protect populations but not necessarily regarded as sufficient solutions to tackle public health challenges. Nevertheless, more rigorous empirical studies should be advanced to provide clearer explanations on whether road safety and public health benefits can indeed emerge from this novel technology.

\section{What is already known on this subject?}

- It is estimated that more than 270000 people die yearly in alcoholrelated crashes globally. To tackle this burden, government interventions, such as laws which restrict blood alcohol concentration levels while driving, have been implemented.

- Ridesharing technologies, such as Uber, have also been regarded as important alternatives to decrease alcoholrelated crashes.

- Effects of network ridesharing on alcohol-related traffic crashes have been studied in the United States and South Africa. Results are mixed, with some studies suggesting reductions in alcohol-related crashes after Uber was introduced, but other studies not observing any change.

- No prior study has considered how ridesharing interacts with government measures that directly tackle alcohol-impaired driving. 


\section{What does this study add?}

- This study is the first to investigate the effect of Uber on alcohol traffic mortality and morbidity in a setting in which two government interventions were purposely introduced to decrease alcohol-impaired driving and its consequences.

- We found evidence that regardless of the city in which Uber is introduced no changes in the alcohol-related injury and traffic fatality rates were observed, but rather both initiatives were more likely to decrease these outcomes.

- More rigorous empirical studies should be advanced to provide clearer explanations on whether public health benefits can indeed emerge from ridesharing technologies.

Contributors JINM designed the study, designed data collection tools, wrote the statistical analysis plan, analysed the data in STATA and wrote the draft paper and revised the final paper to incorporate other co-authors', reviewers' and editors' insights. BB designed the study, wrote the statistical analysis plan, cleaned and analysed the data in SAS and R, created the figures of models and revised and corrected multiple versions of the paper. JS revised and corrected the draft paper and collaborated in the application of new methods. YO revised and corrected the draft paper and collaborated in the application of new methods. AN designed the study and drafted and revised multiple versions of the paper.

Funding This research was funded by the Canadian Institutes of Health Research award number 39587.

Competing interests None declared.

Patient consent for publication Not required.

Provenance and peer review Not commissioned; externally peer reviewed.

Data availability statement Data are available upon reasonable request.

Open access This is an open access article distributed in accordance with the Creative Commons Attribution Non Commercial (CC BY-NC 4.0) license, which permits others to distribute, remix, adapt, build upon this work non-commercially, and license their derivative works on different terms, provided the original work is properly cited, appropriate credit is given, any changes made indicated, and the use is noncommercial. See: https://creativecommons.org/licenses/by-nc/4.0/.

\section{REFERENCES}

1 Vissers LH, Houwing WF. Alcohol-related road casualties in official crash statistics.

Paris: International Transport Forum ITF, 2017: $55 \mathrm{p}$.

2 Albalate D. Lowering blood alcohol content levels to save lives: the European experience. J Policy Anal Manage 2008;27:20-39.

3 Sanchez-Ramirez DC, Voaklander D. The impact of policies regulating alcohol trading hours and days on specific alcohol-related harms: a systematic review. Inj Prev 2017:24:94-100.

4 Babor T, Caetano R, Casswell S, et al. Alcohol: no ordinary commodity. Oxford: Oxford Univeristy Press, 2010.

5 Treno AJ, Johnson FW, Remer LG, et al. The impact of outlet densities on alcohol-related crashes: a spatial panel approach. Accid Anal Preven 2007;39:894-901

6 Fell JC, Fisher DA, Voas RB, et al. The impact of underage drinking laws on alcohol-related fatal crashes of young drivers. Alcohol Clin Exp Res 2009;33:1208-19.

7 Wagenaar AC, Salois MJ, Komro KA. Effects of beverage alcohol price and tax levels on drinking: a meta-analysis of 1003 estimates from 112 studies. Addiction 2009:104:179-90

8 Bergen G, Pitan A, Qu S, et al. Publicized sobriety checkpoint programs: a community guide systematic review. Am J Prev Med 2014;46:529-39.

9 Ditter SM, Elder RW, Shults RA, et al. Effectiveness of designated driver programs for reducing alcohol-impaired driving: a systematic review. Am J Prev Med 2005;28:280-7.

10 Brazil N, Ds K. Uber and metropolitan traffic fatalities in the United States. Am J Epidemio/ 2016;184:192-8.

11 Dills AK, Mulholland SE. Ride-sharing, fatal crashes, and crime, 2016. Available: https://ssrn.com/abstract=2783797 (accessed 15 Dec 2018).

12 Martin-Buck F. Driving safety: an empirical analysis of ridesharing's impact on drunk driving and alcohol-related crime, 2016. Available: http://www.frankmartinbuck.com/ Ridesharing\%20and\%20Alcohol-Related\%20Crime\%20by\%20Frank\%20MartinBuck.pdf (accessed 11 Dec 2018).
13 Greenwood BN, Wattal S. Show me the way to go home: an empirical investigation of ride-sharing and alcohol related motor vehicle fatalities. Manag Inf Syst $Q$ 2017:41:163-87.

14 Peck J. New York City drunk driving after Uber. New York: City University of New York Graduate Center, Ph.D. Program in Economics, 2017.

15 Morrison CN, Jacoby SF, Dong B, et al. Ridesharing and motor vehicle crashes in 4 US cities: an interrupted time-series analysis. Am J Epidemiol 2017;187:224-32.

16 Huang JY, Majid F, Daku M. Estimating effects of Uber ride-sharing service on road traffic-related deaths in South Africa: a quasi-experimental study. J Epidemiol Community Health 2019;73:263-71.

17 OECD. Road safety annual report 2017. Paris: OECD Publishing, 2017.

18 Bernal JL, Cummins S, Gasparrini A. Interrupted time series regression for the evaluation of public health interventions: a tutorial. Int J Epidemiol 2017;46:348-55.

19 Comisión Nacional de Seguridad de Tránsito (CONASET). Observatorio de Seguridad Vial, 2018. Available: https://www.conaset.cl/programa/observatorio-datosestadistical (accessed 15 Oct 2018).

20 National Congress of Chile. Law 20 580. 2012. Available: https://www.conaset.cl/wpcontent/uploads/2016/01/LEY-20580_15-MAR-2012.pdf (accessed 11 Dec 2018).

21 National Congress of Chile. Law 20 770. 2014. Available: https://www.conaset.cl/wpcontent/uploads/2016/01/LEY-20770_16-SEP-2014-5.pdf (accessed 11 Dec 2018).

22 Araya D, Paraje G, Nugent RA. The impact of prices on alcoholic beverage consumption in Chile. PLoS One 2018;13:e0205932.

23 Universidad Alberto Hurtado, Observatorio Social. Informe Ejecutivo. Encuesta Origen Destino de Viajes. 2014. Available: http://www.sectra.gob.cl/biblioteca/detalle1.asp? $\mathrm{mfn}=3253$ (accessed 10 Feb 2020).

24 Uber-Chile. Hechos y Datos Sobre Uber. 2015. Available: https://newsroom.uber.com/ chile/hechos-y-datos-sobre-uber/ (accessed 17 May 2018).

25 Riquelme-Diaz J. Uber en la región de Valparaíso: usuarios gastan en promedio $\$ 3.500$ y lo usan en horas peak. 2016. Available: http://www.soychile.cl/ Valparaiso/Economia-y-Negocios/2016/06/29/402693/Uber-en-la-region-deValparaiso-usuarios-gastan-en-promedio-3500-y-lo-usan-en-horas-peak.aspx (accessed 17 Aug 2018).

26 Ruda. ¡Uber llegó a Conce! 2016. Available: http://www.revistaruda.cl/uber-llego -a-conce/ (accessed 17 Aug 2018).

27 Teletrece. Uber abre convocatoria para conductores de diez nuevas ciudades en Chile. 2017. Available: http://www.t13.cl/noticia/nacional/uber-ya-esta-disponible-dieznuevas-ciudades-chile (accessed 17 May 2018).

28 Comisión Nacional de Productividad. Tecnologías disruptivas: Regulación de Plataformas Digitales. 2018. Available: http://www.comisiondeproductividad.cl/wpcontent/uploads/2018/09/Cap\%C3\%ADtulo-III-Plataformas-de-Transporte.pdf (accessed 15 Dec 2018).

29 Muñoz C. Uber Chile estrena tres nuevas funciones de seguridad para el país. 2018 Available: https://www.fayerwayer.com/2018/11/uber-chile-funciones-seguridad/ (accessed 17 Dec 2018).

30 López CA. Estado habría recaudado al menos US\$ 50 millones adicionales en $2017 \mathrm{si}$ Uber pagara impuestos en Chile. 2018. Available: http://www.economiaynegocios.cl/ noticias/noticias.asp?id=460060 (accessed 17 Dec 2018).

31 Superintendencia de Bancos e Instituciones Financieras Chile. Información financiera. Informe de Tarjetas de Crédito. Available: https://www.sbif.cl/sbifweb/servlet/ InfoFinanciera? indice $=4.1$ \&idCategoria $=564 \&$ tipocont $=568 \#$ accordion6726 (accessed 17 Dec 2018).

32 Subsecretaría de Telecomunicaciones. Telefonía móvil. Available: https://www.subtel. gob.cl/estudios-y-estadisticas/telefonia/ (accessed 17 Dec 2018).

33 Linden A. Conducting interrupted time-series analysis for single-and multiple-group comparisons. Stata J 2015;15:480-500.

34 Instituto de Estudios Urbanos y Territoriales. Índice de Calidad de Vida Urbana Comunas de y Ciudad de Chile. Santiago. 2018. Available: https://www.uc.cl/images/ stories/informacion_institucional/noticias/2018/5_mayo/20180508_ICVU_2018.pdf (accessed 17 Dec 2018).

35 Instituto Nacional de Estadísticas. Censo 2015. Santiago Chile: Instituto Nacional de Estadísticas, 2015.

36 McCleary R, Hay R. Applied time series analysis for the social sciences. Thousand Oaks, CA: Sage Publications, Inc, 1980.

37 SAS. Version 9.4. Cary, NC: SAS Institute Inc, 2014.

38 Nazif-Munoz JI, Quesnel-Vallée A, Van den Berg A. Did Chile's traffic law reform push police enforcement? Understanding Chile's traffic fatalities and injuries reduction. Inj Prev 2015;21:159-65.

39 Castillo-Carniglia Á, Kaufman JS, Pino P. Geographical distribution of alcohol-attributable mortality in Chile: a Bayesian spatial analysis. Addict Behav 2015;42:207-15.

40 Nazif-Muñoz JI, Nandi A, Ruiz-Casares M. Impact of child restraint policies on child occupant fatalities and injuries in Chile and its regions: an interrupted time-series study. Accid Anal Preven 2018;120:38-45.

41 Domeyko A Confesiones de mujeres Uber. Available: http://www.economiaynegocios cl/noticias/noticias.asp?id=254397 (accessed 19 Dec 2018).

42 Servicio Nacional para la Prevención y Rehabilitación del Consumo de Drogas y Alcoho (SENDA). 2018. Décimo Segundo Estudio Nacional de Drogas en Población General. [February 11, 2020]. 